\title{
ANALYSIS OF FUEL CONSUMPTION AND OXIDES OF NITROGEN USING OXYGEN ENRICHED AIR IN COMPRESSION IGNITION ENGINE
}

\author{
Kamalakkannan.K' ${ }^{1}$, Bharath.P ${ }^{2}$ \\ ${ }^{1}$ Associate Professor, ${ }^{2}$ Post graduate student, Department of automobile engineering, Hindustan University, Padur, \\ Chennai, India
}

\begin{abstract}
Pollution is one major factor which affects the environment nowadays, resulting in green house effect and global warming. Suitable methods are introduced to increase the engine fuel economy and bring down the emissions within the tolerable limit. One way of doing it is by inducting oxygen into the combustion chamber since oxygen is a combustion enhancer the amount of oxygen entering into the combustion chamber if increased it would result in better engine performance and lower emissions. Oxygen can be inducted in the intake stroke by the help of an external source and mixing chamber is provided so that it helps in better mixing of air and supplementary oxygen. This additional increase of air will affects all parameters of the engine like operating temperature, fuel consumption, Brake power, emissions, and heat release but only fuel consumption and Oxides of Nitrogen $\left(N O_{x}\right)$ alone is analyzed. Load test was conducted on a compression Ignition engine for various concentration of oxygen from (21\% to $27 \%)$ with an interval of 2\%. This experimental study shows better fuel economy and better brake specific fuel consumption but led to a very high percentage of Oxides of Nitrogen $\left(\mathrm{NO}_{x}\right)$ emission and lower carbon monoxide $(\mathrm{CO})$, hydro carbon $(\mathrm{HC})$ emission.
\end{abstract}

Keywords: NOx emission, Fuel economy, Diesel engine, Oxygen enriched air.

\section{INTRODUCTION}

A Diesel engine is an internal combustion engine which uses the heat of compression to initiate ignition in the combustion chamber [11]. Diesel engine has the highest thermal efficiency of all standard internal combustion engine because of the nature of the fuel used pollutants such as soot particles, carbon monoxide, oxides of nitrogen has become a major environmental issue.

Diesel engine always operated in excess air conditions hence air entering has about $78 \%$ Nitrogen improving engine performance and reducing pollution has always been a problem because higher operating temperature would result in better engine performance but will lead to $\mathrm{NO}_{\mathrm{x}}$ emission[11]. To improve the performance and fuel economy of the engine nitrogen getting into the engine has to be eliminated.

To overcome the said problem $100 \%$ oxygen in the intake can be given which would result in zero $\mathrm{NO}_{\mathrm{x}}$ emission. But this method has a lot of limitation. Secondly the nitrogen entering into the engine can be replaced by different kind of gas (e.g.: Inert gas) in the intake system so that it doesn't interact with the combustion process and should not be a pollutant to the performing system or to the environment.
These both methods have serious limitations. Another way of doing this is by increasing the percentage of oxygen in the intake air which will effectively replace the nitrogen from getting into the engine. This will serve as a suitable alternative.

In this study the effect of various percentage of oxygen in the intake air is studied with respect to fuel consumption and emission parameters.

\section{EXPERIMENTAL SETUP}

Test was conducted on a single cylinder, naturally aspirated, air cooled, and constant speed greaves engine. An eddy current Dynamometer was used as the Loading device and a Krypton gas analyzer was used for the study of the exhaust gases. The specifications of the engine are given in the Table 1.

Table -1: Engine specifications

\begin{tabular}{|c|c|}
\hline Engine type & $\begin{array}{c}\text { Naturally aspirated, } \\
\text { air cooled, constant } \\
\text { speed, greaves engine }\end{array}$ \\
\hline No of cylinders & 1 \\
\hline Compression ratio & $18: 1$ \\
\hline Bore & $68 \mathrm{~mm}$ \\
\hline
\end{tabular}




\begin{tabular}{|c|c|}
\hline Stroke & $78 \mathrm{~mm}$ \\
\hline B.H.P & 5 \\
\hline Fuel & Diesel \\
\hline Specific gravity & 0.8275 \\
\hline Loading device & $\begin{array}{c}\text { Eddy current } \\
\text { dynamometer }\end{array}$ \\
\hline
\end{tabular}

The source of oxygen is a commercial used oxygen cylinder which is attached to a flow meter which is fitted to a flame trap and then goes to a mixing chamber which helps in mixing of air and the supplement oxygen. Then it is feed into the engine.

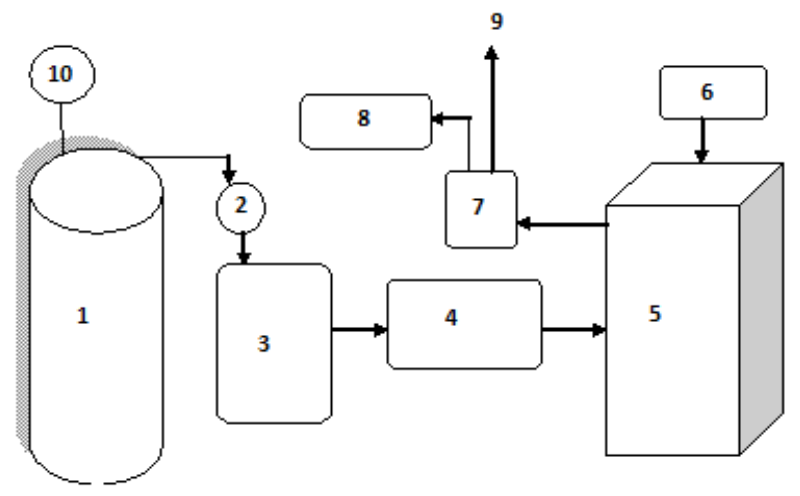

(1) Oxygen cylinder; (2) Flow meter; (3) Flame trap; (4) Engine; (5) Engine; (6) Loading Device; (7) Exhaust gas; (8) Krypton gas analyzer; (9) To Atmosphere

Fig -1: Experimental setup

Test was taken for all the different percentage of Oxygen in the intake air. The amount of oxygen entering is monitored in such a way that it doesn't exceed $28 \%$ because higher percentage of oxygen would result in very high heat release and may result in explosion.

The quantity of oxygen sent additionally into the engine is given in the table 2 .

Table -2: Quantity of oxygen supplemented

\begin{tabular}{|l|l|l|l|}
\hline Percentage & $\begin{array}{l}\text { Liters per } \\
\text { minute }\end{array}$ & $\mathrm{O}_{2} \%$ in CC & $\begin{array}{l}\text { Total } \mathrm{O}_{2} \\
\text { in CC }\end{array}$ \\
\hline $21 \%$ & $\begin{array}{l}\text { No additional } \\
\mathrm{O}_{2}\end{array}$ & 918 & 918 \\
\hline $23 \%$ & 2.5 & $918+42$ & 959 \\
\hline $25 \%$ & 5 & $918+83$ & 1001 \\
\hline $27 \%$ & 7.5 & $918+125$ & 1043 \\
\hline
\end{tabular}

\section{RESULTS AND DISCUSSION}

The enrichment of oxygen in the intake air would help in better combustion and result in higher heat release for the same quantity of fuel.

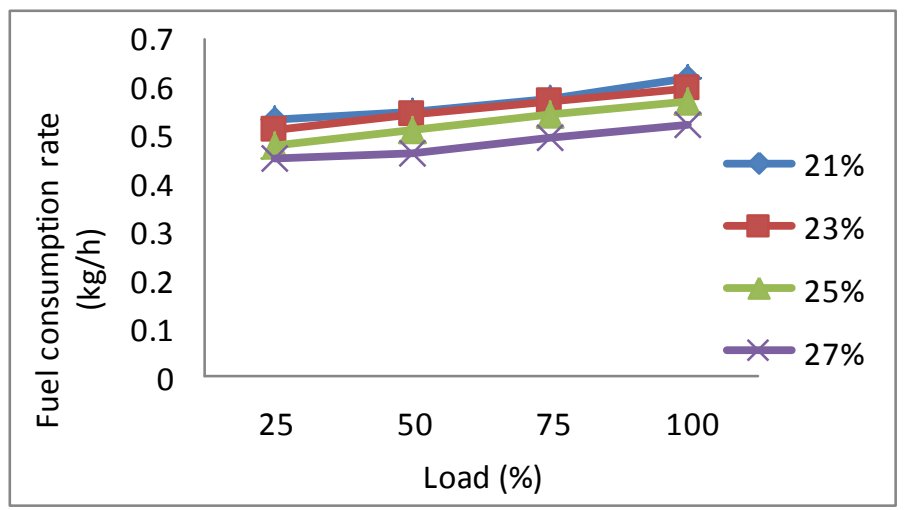

Graph -1: Load vs fuel consumption rate

By increasing the percentage of oxygen in the intake air from ( $21 \%$ to $27 \%$ ) the variation can be found. It is observed that for normal $21 \%$ oxygen level the engine had a maximum value of $0.6206 \mathrm{~kg} / \mathrm{h}$ at $100 \%$ load when taken for $23 \%$ of oxygen enrichment there was very significant change when compared with $25 \%$ and $27 \%$ of oxygen there was a distinct change of $9 \%$ and $14 \%$ decrease was found. This shows that the same work can be done by the engine at less fuel consumption rate.

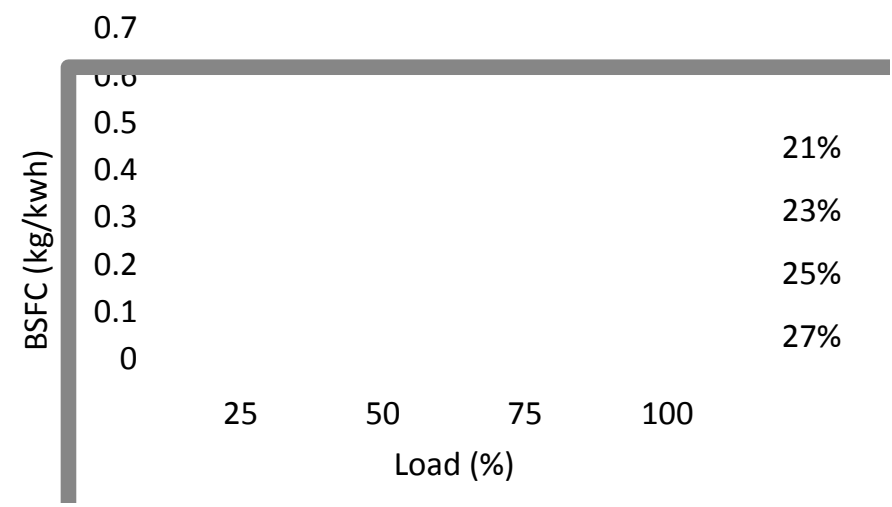

Graph -2: Load vs Brake specific Fuel consumption

The Brake specific fuel consumption(BSFC) also showed a distinct variation at higher percentage of oxygen levels in the intake air for $21 \%$ and $23 \%$ of oxygen levels the specific brake power was high as $0.645 \mathrm{~kg} / \mathrm{wh}$ at minimum load and at high load conditions the amount of fuel consumed for unit brake power reduced by about $35 \%$ for oxygen enrichment of $25 \%$ and $27 \%$ the variation was distinct there was a reduction of $11 \%$ and $18 \%$ less fuel consumption at all loads which shows 
that higher oxygen percentage in the intake air results in better economy.

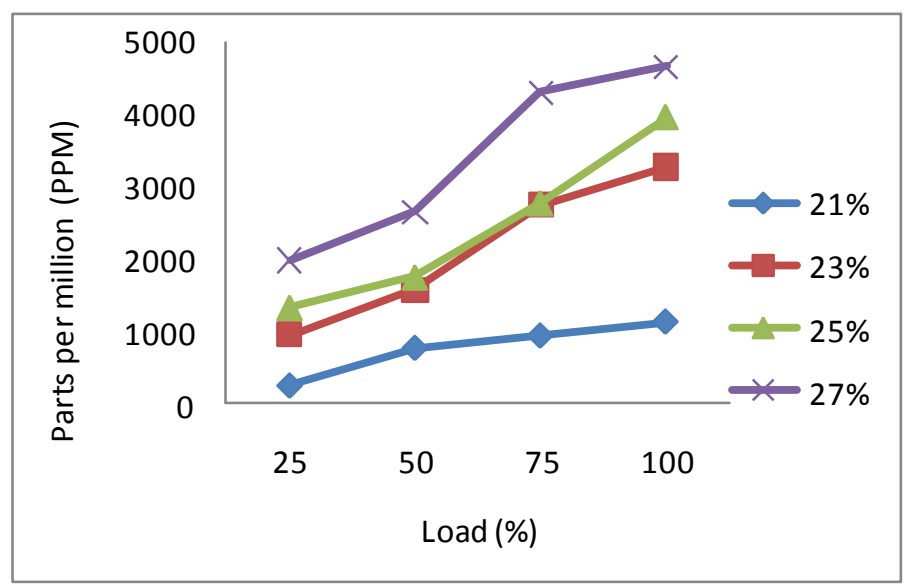

Graph -3: Load vs. $\mathrm{NO}_{\mathrm{x}}$

$\mathrm{NO}_{\mathrm{x}}$ parameter for different percentage of oxygen shows wide variations because oxygen which is inducted inside the chamber increases the operating temperature which makes the atmospheric nitrogen into atomic nitrogen which has more affinity towards oxygen which results in the formation of $\mathrm{NO}_{\mathrm{x}}$ in the engine.

When compared the $\mathrm{NO}_{\mathrm{x}}$ curve for all $23 \%, 25 \%$, and $27 \%$ of oxygen there is nearly $400 \%, 540 \%$ and $800 \%$ of $\mathrm{NO}_{\mathrm{x}}$ increase when compared with normal $21 \%$ Oxygen level operating condition

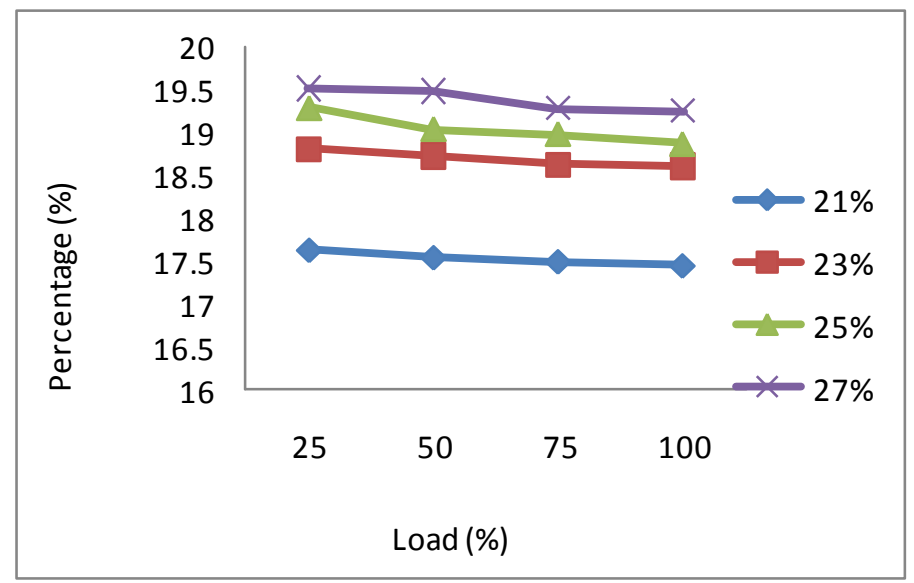

Graph -4: Load vs Oxygen percentage in exhaust

The percentage of oxygen in the exhaust also increased considerably when more oxygen is sent into the engine $\mathrm{CO}$ level reduced by $33 \%, 39 \%$, and $53 \%$ for the respective oxygen percentage of $23 \%, 25 \%$, and $27 \%$ in the intake air.
Table -3: Comparison of all four graphs at Peak load

\begin{tabular}{|c|c|c|c|c|}
\hline Percentage & $\begin{array}{c}\text { Fuel } \\
\text { consumption }\end{array}$ & BSFC & $\mathrm{NO}_{\mathrm{x}}$ & $\begin{array}{c}\mathrm{O}_{2} \% \text { in } \\
\text { exhaust }\end{array}$ \\
\hline $21 \%$ & 0.62 & 0.4106 & 1134 & 17.44 \\
\hline $23 \%$ & 0.595 & 0.4014 & 3278 & 18.61 \\
\hline $25 \%$ & 0.572 & 0.3845 & 3956 & 18.87 \\
\hline $27 \%$ & 0.523 & 0.3456 & 4656 & 19.26 \\
\hline
\end{tabular}

The comparison of all four values show that increasing the oxygen percentage in the intake reduces the fuel consumption and it has the highest percentage of oxygen usage of about $23 \%$ and the only limitation is that it has more $\mathrm{NO}_{\mathrm{x}}$.

\section{CONCLUSIONS}

The use of oxygen enrichment on diesel engine under different load condition was studied and the main observations are as follows:

1. Fuel consumption rate decreases for higher oxygen percentage in the intake air.

2. The amount of fuel consumed for unit brake power is high at minimum load, and reduces when the load increases and this happens for all oxygen percentages in the intake air.

3. Oxygen which is coming out of the exhaust also increases with respect to the percentage of oxygen in the intake air.

4. $\mathrm{CO}$ drops a very high percentage with respect to oxygen induction in the intake as oxygen helps in better combustion.

5. $\mathrm{NO}_{\mathrm{x}}$ which has increased exponentially can be reduced be using suitable after treatment methods or optimum level of $\mathrm{NO}_{\mathrm{x}}$ to the percentage of oxygen in the intake air have to be found so that the $\mathrm{NO}_{\mathrm{x}}$ is kept under tolerable limit.

\section{ACKNOWLEDGEMENTS}

The authors are thankful for the full support provided by the college (Hindustan University) and Department of automobile engineering for giving the opportunity to do this research work.

\section{REFERENCES}

[1]. B Lakshmana Swamy1, Dr. B Sudheer Prem Kumar, Dr. K Vijay Kumar Reddy " Reduction of Diesel Engine Emissions and Its Analysis by Using Exhaust Gas Recirculation at Various Cooling Rates" August 2013224 International Journal of Engineering and Innovative Technology (IJEIT) Volume 3, Issue 2.

[2]. K.Rajkumari and P. Govindarajan "Experimental Investigation of Oxygen Enriched air intake on Combustion Parameters of a Single Cylinder Diesel Engine" 2010, 36213627 International Journal of Engineering Science and Technology Vol. 2(8) 
[3]. Operational and environmental evaluation of Diesel engines burning oxygen enriched intake air or oxygen enriched fuels - SAE Technical papers - paper number: 2004 - 01- 2924

[4]. Theodoros $\mathrm{C}$ et al., DI Diesel Engine Performance and Emissions from the Oxygen Enrichment of Fuels with Various Aromatic Content, Internal Combustion Engines Laboratory, National Technical University of Athens

[5]. Lei, J., Bi, Y. and Shen, L., "Performance and emission characteristics of diesel engine fueled with ethanol-diesel blends in different altitude regions", hindawi publishing corporation, 2011.

[6]. Arrègle, J., López, J. J., García, J. M., and Fenollosa, C., "Development of a zero-dimensional diesel combustion model. Part 1: analysis of the quasi steady diffusion combustion phase", appl. Thermal eng., Vol. 23, No. 11, 2003, pp. $1301-131$

[7]. Assians D.N. et al., Study of using oxygen-enriched combustion for locomotive diesel engine, Journal of engineering for gas turbines and power Y.2001, vol.123,No.1.

[8]. Donahue, R. J. and Foster, D. E.,'Effect of oxygen enhancement on the emission from DI diesel via manipulation of fuel and combustion chamber gas composition", SAE paper, No. 2001-01-0512

[9]. Song, J., Zello, V. and Boehman, A. L., "Comparison of the impact of intake oxygen enrichment and fuel oxygenation on diesel particulate emissions", fuel chemistry division preprints, 2002.

[10]. Anand, R. and Mahalakshmi, N. V., "The effects of oxygen enrichment with intake air in a direct injection diesel engine", IE (I) Journal-Mc, Vol. 90, 2010, pp.44-47.

[11]. Internal combustion engines by V.Ganesan, Tata McGraw-Hill publishing company limited.

\section{BIOGRAPHIES}

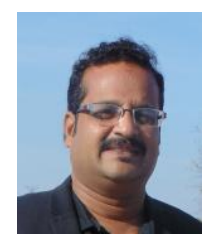

Kamalakkannan. K, AssociateProfessor, Department of Automobile Engineering, Hindustan University, Chennai, Mail id: kamalakannan.ka@gmail.com

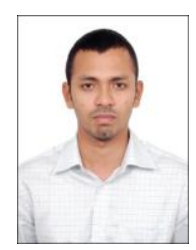

Bharath. P, M.Tech (ICE), Final year student, Hindustan University, Padur, Chennai, India. Mail id: bharath.prabhacar@gmail.com 